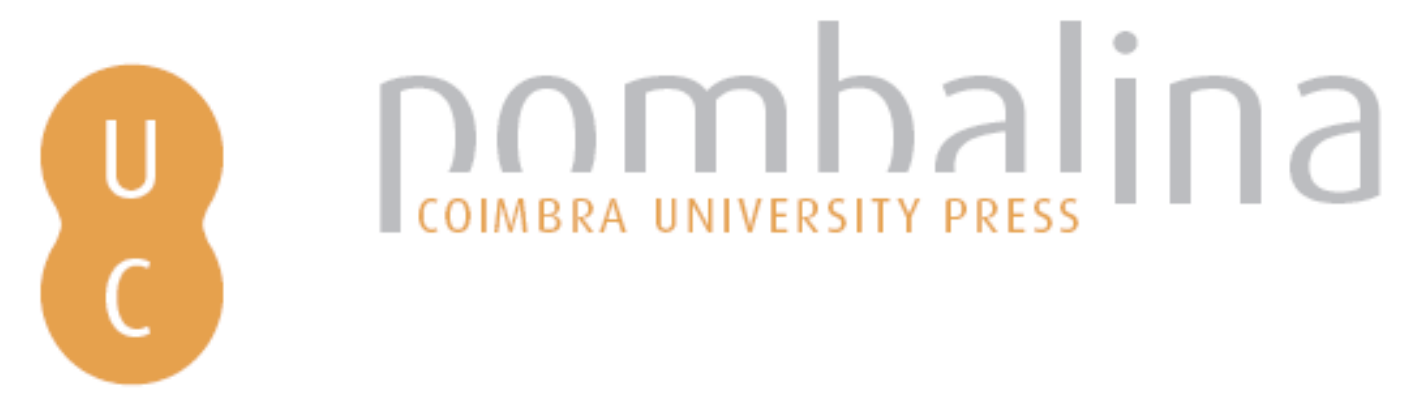

\title{
Ocorrência de eventos extremos de precipitação em Campina Grande - Paraíba,
} Brasil

\begin{tabular}{ll} 
Autor(es): & $\begin{array}{l}\text { Medeiros, Raimundo Mainar de; Sousa, Edicarlos Pereira de; Gomes } \\
\text { Filho, Manoel Francisco }\end{array}$ \\
Publicado por: & $\begin{array}{l}\text { Imprensa da Universidade de Coimbra; RISCOS - Associação } \\
\text { Portuguesa de Riscos, Prevenção e Segurança }\end{array}$ \\
$\begin{array}{ll}\text { URL } \\
\text { persistente: }\end{array}$ & URI:http://hdl.handle.net/10316.2/34875 \\
DOI: & DOI:http://dx.doi.org/10.14195/978-989-96253-3-4_74 \\
Accessed : & 26-Apr-2023 08:07:06 \\
\hline
\end{tabular}

A navegação consulta e descarregamento dos títulos inseridos nas Bibliotecas Digitais UC Digitalis, UC Pombalina e UC Impactum, pressupõem a aceitação plena e sem reservas dos Termos e Condições de Uso destas Bibliotecas Digitais, disponíveis em https://digitalis.uc.pt/pt-pt/termos.

Conforme exposto nos referidos Termos e Condições de Uso, o descarregamento de títulos de acesso restrito requer uma licença válida de autorização devendo o utilizador aceder ao(s) documento(s) a partir de um endereço de IP da instituição detentora da supramencionada licença.

Ao utilizador é apenas permitido o descarregamento para uso pessoal, pelo que o emprego do(s) título(s) descarregado(s) para outro fim, designadamente comercial, carece de autorização do respetivo autor ou editor da obra.

Na medida em que todas as obras da UC Digitalis se encontram protegidas pelo Código do Direito de Autor e Direitos Conexos e demais legislação aplicável, toda a cópia, parcial ou total, deste documento, nos casos em que é legalmente admitida, deverá conter ou fazer-se acompanhar por este aviso.

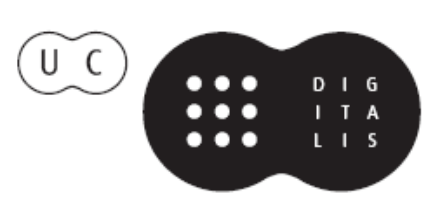



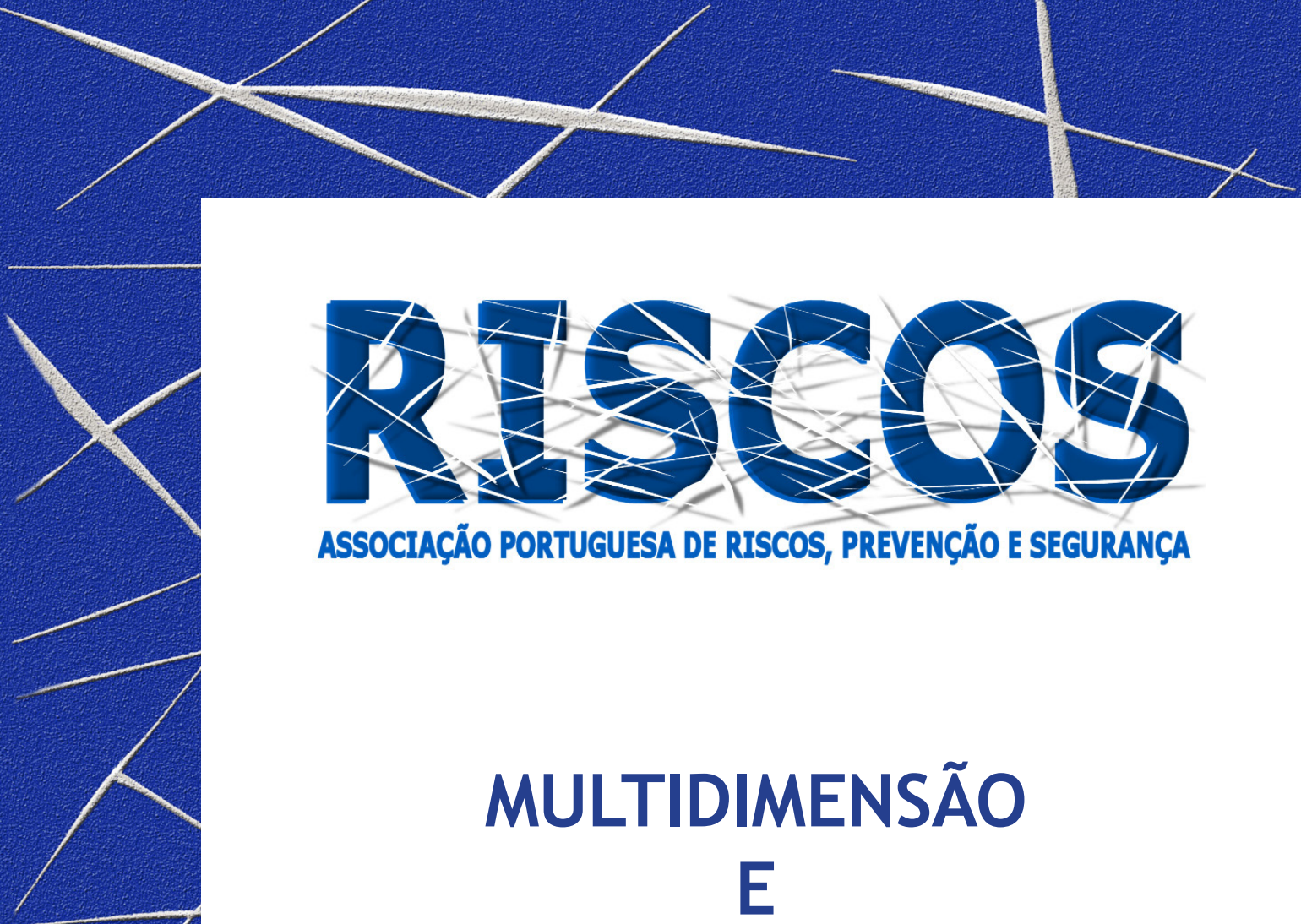

ASSOCIAÇÃO PORTUGUESA DE RISCOS, PREVENCCÃO E SEGURANÇA

MULTIDIMENSÃO

E
TERRITÓRIOS DE RISCO

III Congresso Internacional

I Simpósio Ibero-Americano

VIII Encontro Nacional de Riscos

Guimarães

2014 


\title{
OCORRÊNCIA DE EVENTOS EXTREMOS DE PRECIPITAÇÃO EM CAMPINA GRANDE - PARAÍBA, BRASIL
}

\author{
Raimundo Mainar de Medeiros \\ Doutorando em Meteorologia -Universidade Federal de Campina Grande \\ mainarmedeiros@gmail.com \\ Edicarlos Pereira de Sousa \\ Doutorando em Meteorologia - Universidade Federal de Campina Grande \\ edicarlos.p.sousa@gmail.com \\ Manoel Francisco Gomes Filho \\ Departamento de Ciências Atmosféricas da Universidade Federal de Campina Grande \\ mano@dca.ufcg.edu.br
}

\begin{abstract}
RESUMO
Os eventos extremos de precipitação, como as chuvas fortes e as secas prolongadas, têm sido a causa de vários desastres naturais. Analisaram-se as ocorrências de eventos extremos de precipitação em Campina Grande, com dados diários de precipitação que compreende os anos de 1970-2010 adquiridos da Agência Executiva de Gestão das Águas do Estado da Paraíba. Os eventos extremos analisados foram os de maior intensidade de precipitação diária para os anos estudados. Os resultados mostraram que houve mudança no comportamento das ocorrências de precipitação a partir da década de 70 na área de estudo. Ocorreu intensificação na precipitação máxima apresentando maior número de eventos com valores de precipitação superior a $80 \mathrm{~mm}$. Não houve, de modo geral, relação direta entre a intensificação na precipitação e ocorrências com eventos de ENOS. Eventos extremos foram evidentes entre os meses da estação chuvosa, com $88 \%$ das ocorrências e $12 \%$ na estação seca.
\end{abstract}

Palavras-chave: ENOS, análise, mudanças climáticas, eventos extremos.

\section{Introdução}

As constantes mudanças no clima estão provocando aumento nas ocorrências de eventos climáticos extremos no mundo inteiro. No Brasil, esses eventos ocorrem, principalmente, como enchentes (fortes chuvas) e secas prolongadas (Marengo et al.,2010). No Nordeste do Brasil (NEB) os impactos são ainda maiores devido à grande variabilidade na ocorrência de precipitação dessa região. Os principais sistemas responsáveis pela ocorrência de precipitação no NEB são: Zona de Convergência Intertropical (ZCIT), Vórtices Ciclônico de Altos Níveis (VCAN), Linha de Instabilidade (LI), Zona de Convergência do Atlântico Sul (ZCAS), Brisas (Marítima e Terrestres) e as Perturbações Ondulatórias nos ventos Alísios (POAS) (Molion e Bernardo, 2002). 0 El Niño - Oscilação Sul (ENOS) é outro modo de variabilidade climática que influência na ocorrência de precipitação do NEB.

Os eventos extremos são os principais causadores da maioria dos desastres naturais ocorridos nos últimos anos e têm afetado diretamente a população. Como consequências destes desastres ocorrem perdas de vidas humanas e animal, prejuízos na economia, agricultura, transporte, saúde e moradia além de causar impactos graves aos mais variados ecossistemas.

As fortes chuvas provocam inundações, alagamento, cheias em zonas rural e urbanas, e consequentemente mortes por afogamentos, deslizamentos de terras, desabamentos de prédios entre outros desastres.

Secas prolongadas tornam a água um recurso indisponível e até escasso provocando a migração da população para outras regiões em busca de melhores condições de sobrevencia de vida. A falta de precipitação atrapalha o desenvolvimento da agrícola e a agropecuária trazendo 
consequências negativas para a economia da região. Nas plantas, a falta de água prejudica o seu desenvolvimento em suas diversas fases de crescimento, principalmente, quando este problema ocorre durante fases fenológicas nas quais elas necessitam de maiores quantidades de água, como, por exemplo, durante a floração e frutificação (Fietz et al., 1998).

A ausência de chuvas provoca baixa disponibilidade de água no solo que limita o desenvolvimento das plantas provocando perdas na produtividade final. As culturas agrícolas também podem ser afetadas pelo excesso de água que mata as plantas por afogamento quando essas estão na fase inicial de crescimento.

De maneira geral, pode-se dizer que o aquecimento global, em um futuro próximo, tende a apresentar um cenário de clima mais extremo, com maiores ocorrências de estiagens e inundações. Logo, é importante saber a frequência e a intensidade com que esse fenômeno meteorológico vem ocorrendo nas últimas décadas.

\section{Material e Métodos}

O estudo da variabilidade das ocorrências de eventos extremos de precipitação foi concretizado em Campina Grande - PB. Segundo Thornthwaite o clima é: $C_{2}$ SW (clima subúmido, moderada deficiência de água no verão, com índice de aridez entre 16,7 e 33,3, mesotérmicos e com vegetação durante o ano todo). Campina Grande situa-se, entre o Litoral e o Sertão da Paraíba, usufruindo assim, de um clima menos árido. Por estar localizado em uma região alta, beneficiase de temperaturas menores e de uma ótima ventilação, o que proporciona um clima ameno e agradável. A temperatura média anual oscila em torno dos $23,3{ }^{\circ} \mathrm{C}$, a máxima em torno dos 30,9 ${ }^{\circ} \mathrm{C}$ e a mínima em torno de $18,4{ }^{\circ} \mathrm{C}$. A umidade relativa do ar, na área urbana, varia normalmente entre 75 a $83 \%$.

Dados diários de precipitação pluviométrica que compreende os anos de 1970 - 2010 foram fornecidos pela Agência Executiva de Gestão das Águas do Estado da Paraíba (AESA). As análises estatísticas dos dados foram desenvolvidas por planilhas eletrônicas. Avaliou-se a ocorrência dos eventos extremos de precipitação de maior intensidade em cada ano, como também o dia de sua ocorrência.

A análise das características de eventos extremos com os eventos de ENOS - El Niño Oscilação Sul (Tabela II) foi realizado pela classificação dos anos, em anos de ocorrência de um evento de El Niño e anos de ocorrência de um evento de La Niña, da série de estudo.

\section{Resultados e Discussão}

$\mathrm{Na}$ análise das ocorrências de eventos extremos de precipitação do período de 1970-2010 (Figura 1) demonstram que na década de 70 ocorreu maior variabilidade com índices de precipitação variando, na sua maioria, entre 50 e $190 \mathrm{~mm}$, com destaque para os anos de 1972, 1981, 1985, 1991 e 2001 que os índices pluviométricos foram maiores que $80 \mathrm{~mm}$, exceto os anos de 1974 (190,8 mm e 1978 com 105 mm.). A partir da década de 80 ocorreu variabilidade na intensificação da precipitação máxima anual apresentando menores números de eventos com índices pluviométricos inferiores a $40 \mathrm{~mm}$ nos anos de 1982, 1987, 1995, 1997 e 1998. Nos últimos anos (2000 a 2010) os eventos extremos oscilaram na sua flutuação espaço-temporal com precipitação máxima diária oscilando entre 30,1 a 85,4 mm.

Notou-se também que não houve relação direta entre a intensificação na precipitação e ocorrências com eventos de ENOS (Figura 1). Porém, em alguns anos a relação foi constatada. Em geral, no nordeste os ENOS alteram os totais pluviométricos da região e também a ocorrência 
de períodos secos (Carvalho, 2009). Eventos extremos de precipitação são mais evidentes entre os meses da estação chuvosa que se estende de março a julho, (Tabela I), com 18 ocorrências, de um total de 40 , representando $88 \%$ de chances de ocorrência. Nesse período foram registrados os eventos mais intensos com valores superiores a $80 \mathrm{~mm}(1972 ; 1978 ; 1987 ; 1991$ e 2001) A estação seca (setembro - fevereiro) exibiu 15 ocorrências de eventos extremos de precipitação representando assim $37,2 \%$ de chances de ocorrência. Porém, a maioria desses eventos possuiu valores de precipitação pouco menor que $55 \mathrm{~mm}$ com exceção dos anos de 1970-1979 que apresentou 17 mm, 1980-1989 com 30 mm, 1990-1999 com 38,3 mm e 2000-2009 com 73,9 mm, respectivamente. Esses eventos apesar de não serem tão frequentes possuem grande quantidade de água que é suficiente para proporcionar grandes estragos e prejuízos locais.

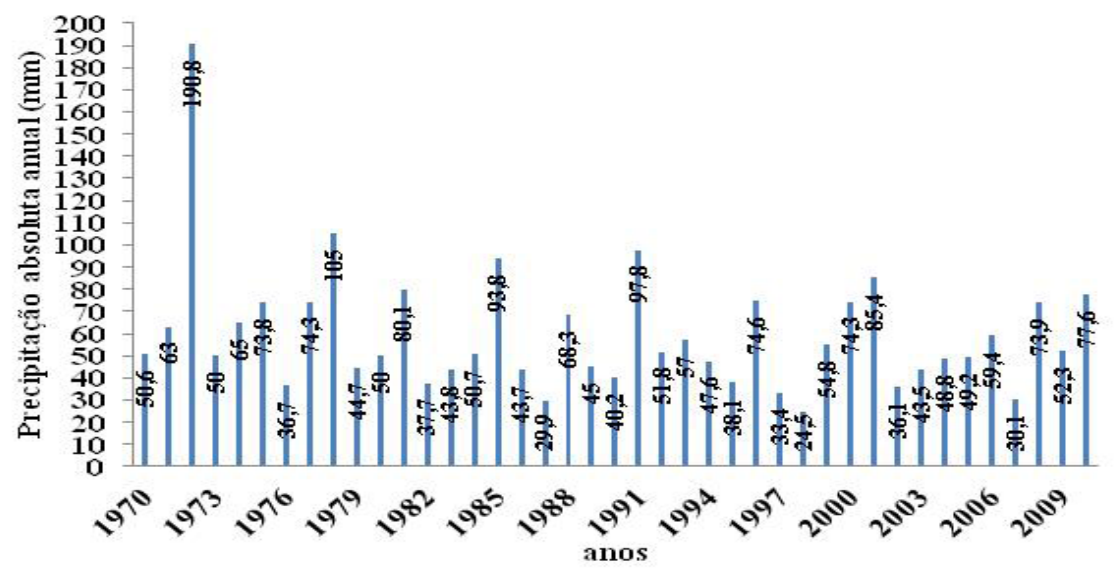

Figura 1. Precipitação máxima anual $(\mathrm{mm})$ durante o período de 1970 a 2010 em Campina Grande, PB.

Tabela I. Dia da ocorrência da máxima precipitação anual durante o período de 1970 a 2010 em Campina Grande, PB.

\begin{tabular}{cccccccc}
\hline Ano & Dia/Mês/Índice & Ano & Dia/Mês/Índice & Ano & Dia/Mês/Índice & Ano & Dia/Mês/Índice \\
\hline 1970 & $27 / 04-50,6$ & 1971 & $09 / 04-63,0$ & 1972 & $20 / 03-190,8$ & 1973 & $29 / 04-50,0$ \\
1974 & $08 / 07-65,0$ & 1975 & $03 / 07-73,8$ & 1976 & $11 / 02-36,7$ & 1977 & $07 / 04-74,3$ \\
1978 & $10 / 03-105,0$ & 1979 & $20 / 05-44,7$ & 1980 & $03 / 03-50,0$ & 1981 & $15 / 03-80,1$ \\
1982 & $26 / 02-37,7$ & 1983 & $07 / 04-43,8$ & 1984 & $19 / 05-50,7$ & 1985 & $13 / 02-93,8$ \\
1986 & $02 / 04-43,7$ & 1987 & $01 / 04-29,9$ & 1988 & $10 / 08-68,3$ & 1989 & $09 / 07-45,0$ \\
1990 & $27 / 05-40,2$ & 1991 & $28 / 03-97,8$ & 1992 & $14 / 02-51,8$ & 1993 & $10 / 06-57,0$ \\
1994 & $15 / 03-47,6$ & 1995 & $03 / 07-38,1$ & 1996 & $30 / 05-74,6$ & 1997 & $15 / 04-33,4$ \\
1998 & $29 / 03-24,5$ & 1999 & $15 / 03-54,8$ & 2000 & $20 / 02-74,3$ & 2001 & $13 / 03-85,4$ \\
2002 & $15 / 02-36,1$ & 2003 & $05 / 06-43,5$ & 2004 & $24 / 01-48,8$ & 2005 & $24 / 01-49,2$ \\
2006 & $21 / 03-59,4$ & 2007 & $01 / 03-30,1$ & 2008 & $19 / 03-73,9$ & 2009 & $20 / 02-52,3$ \\
2010 & $18 / 06-77,6$ & & & & & & \\
\hline
\end{tabular}


Tabela II. Período, Classificação (Classif.) e Intensidade (Intensid.) do El Niño - Oscilação Sul no período de 1970 a 2010.

\begin{tabular}{|c|c|c|c|c|c|c|c|c|}
\hline Período & Classif. & Intensid. & Período & Classif. & Intensid. & Período & Classif. & Intensid. \\
\hline $1972-1973$ & El Niño & Forte & 1973-1976 & La Niña & Forte & 1976-1977 & El Niño & Fraco \\
\hline $1977-1978$ & El Niño & Fraco & $1979-1980$ & El Niño & Fraco & $1982-1983$ & El Niño & Forte \\
\hline $1983-1984$ & La Niña & Fraco & 1984-1985 & La Niña & Fraco & $1986-1988$ & El Niño & Moderado \\
\hline $1988-1989$ & La Niña & Forte & 1990-1993 & El Niño & Forte & $1990-1993$ & El Niño & Forte \\
\hline $1994-1995$ & El Niño & Moderado & 1995-1996 & La Niña & Fraco & 1997-1998 & El Niño & Forte \\
\hline $1998-2001$ & La Niña & Moderado & $2002-2003$ & El Niño & Moderado & 2004-2007 & El Niño & Forte \\
\hline 2008 & La Niña & Forte & $2009-2010$ & El Niño & Fraco & & & \\
\hline
\end{tabular}

\section{FONTE: CPTEC}

\section{Conclusão}

Ocorrência de mudança no comportamento das precipitações a partir do início da década de 70, na região de estudo, variabilidade espaço-temporal na intensificação da precipitação máxima anual apresentando maior número de eventos com valores de precipitação igual ou superior a $80 \mathrm{~mm}$;

Não houve relação direta entre a intensificação na precipitação e ocorrências com eventos de ENOS. Ressaltando que em alguns anos perceberam-se as influências do ENOS;

Eventos extremos de precipitação foram mais evidentes entre os meses da estação chuvosa com $88 \%$ das ocorrências e apenas $12 \%$ foram observados na estação seca.

\section{Agradecimentos}

Á CAPES pela concessão da bolsa de estudo e a elaboração da pesquisa.

\section{Bibliografia}

CARVALHO, A. L.; SOUZA, J. L.; LYRA, G. B.; PORFIRIO, A. C. S.; FERREIRA JUNIOR, R. A.; SANTOS, M. A.; WANDERLEY, H. S. Probabilidade de ocorrência de períodos secos para a região de Rio Largo, Alagoas. In: Congresso Brasileiro de Agrometeorologia, XVI, Belo Horizonte - MG, Anais....(CDRom), 2009.

CPTEC/INPE. Disponível em: http://enos.cptec.inpe.br/tab_elnino.shtml e http://enos.cptec.inpe.br/tab_ lanina.shtml. Acessado em março. 2009.

FIETZ, C. R.; FRIZZONE, F. A.; FOLEGATTI, M. V. Probabilidade de ocorrência de períodos secos e chuvosos na região de Dourados, MS. Irriga (Botucatu), Botucatu, v.3, n.1, p. 16-22, 1998.

MARENGO, J. A.; SCHAEFFER, R.; ZEE, D.; PINTO, H. S. Mudanças climáticas e eventos extremos no Brasil. Disponível em: http://www.fbds.org.br/cop15/FBDS_MudancasClimaticas.pdf. Acessado em outubro de 2010.

MEDEIROS, R. M. Estudo agrometeorológico para o estado da Paraíba. p.128, 2013. Ed. Avulsa.

MOLION, L. C. B.; BERNARDO, S. Uma revisão da dinâmica das chuvas no Nordeste brasileiro. Revista Brasileira de Meteorologia, v.17, p.1-10, 2002.

STERN, R. D.; RIJKS, D.; DALE, I.; KNOCK, J. Instat Climatic Guide. P. 325. Oct. 2005. 